\title{
SYNTHESIS OF MAGNETIC VINYLPHENYL BORONIC ACID MICROPARTICLES AND ITS SURFACE CATALYTIC PERFORMANCE IN ESTERIFICATION OF PROPIONIC ACID WITH METHANOL
}

\author{
Ali KARA ${ }^{1, *}$, Beyhan ERDEM ${ }^{1}$ \\ ${ }^{1}$ Department of Chemistry, Faculty of Science and Arts, Uludağ University, Bursa, Turkey
}

\begin{abstract}
Magnetic vinylphenyl boronic acid microparticles, poly(ethylene glycol dimethacrylate-vinylphenyl boronic acid) [mpoly(EGDMA-VPBA)], produced by suspension polymerization, was found to be efficient solid acid catalyst for the esterification of methanol and propionic acid. Characterization techniques such as FT-IR, Elemental analyses, ICP-AES, ESR, SEM and $\mathrm{N}_{2}$ sorption showed that both of $\mathrm{Fe}_{3} \mathrm{O}_{4}$ and $\mathrm{H}_{2} \mathrm{SO}_{4}$ are bonded to the polymer successfully. Esterification was studied for different molar percentages of $\mathrm{H}_{2} \mathrm{SO}_{4}$ at temperature range of $50-70{ }^{\circ} \mathrm{C}$. The apparent activation energy was found to be $28.4 \mathrm{kj} \cdot \mathrm{mol}^{-1}$ for $10 \% \mathrm{H}_{2} \mathrm{SO}_{4}$ doped m-poly(EGDMA-VPBA). Combining of strong acid $\mathrm{H}_{2} \mathrm{SO}_{4}$ with m-poly(EGDMA-VPBA), leads to materials with different functional properties. In addition, $\mathrm{H}_{2} \mathrm{SO}_{4}$ species could be introduced into the structure as acid centers, therefore this micro-dimensional catalyst has potential candidate for applications in the catalytic esterifications such as propionic acid with methanol.
\end{abstract}

Keywords: Magnetic polymer, Esterification, M-Poly(EGDMA-VPBA), Acid catalyst.

\section{INTRODUCTION}

The esterification reaction is a liquid-phase process, where the limiting conversion of the reactants is determined by equilibrium [1]. Despite the strong catalytic effect, the use of homogeneous catalyst suffers from several drawbacks, such as the existence of side reactions, corrosion of the equipment and the need to deal with acidic wastes [2-5]. The use of solid acid catalyst has received great attention because of distinct advantages, such as the higher purity of the products and easily removing of catalyst from the reaction mixture [6-7]. Heterogeneously catalysed chemical reactions are dramatically influenced by the strength and the number of acid sites as well as the morphology of the support (surface area, pore size, etc.) [8]. Since the surface modification permits tailoring of the surface properties for a potential application, so catalysis, functionalizing the surface of polymeric materials with organic groups have been investigated extensively [9]. Conventionally, boronic acid carrying agarose or acrylamide-based polymeric beads have been used in chromatographic studies involving separation [1014]. Their unique properties as mild organic Lewis acids and their mitigated reactivity profiles, coupled with their stability and ease of handling, makes boronic acids a particularly attractive class of synthetic intermediates. Moreover, because of their low toxicity and their ultimate degradation into the environmentally friendly boric acid, boronic acid can be regarded as "green" compounds [15]. A combination of sulfuric acid and $\mathrm{H}_{3} \mathrm{BO}_{3}$ is useful for the direct esterification of phenols, a reaction that usually fails even with strong mineral acids. Under $\mathrm{H}_{2} \mathrm{O}$ removal, phenyl benzoate is produced in a 94 $\%$ isolated yield [16]. Trifluorobenzene boronic acid has also been proposed as an acylation catalyst, which is, however, more effective for amines than for alcohols [17].

Studies on the preparation of various magnetic polymer microspheres have attracted more and more attention because magnetic seperations are relatively rapid and easy, requiring simple equipment as compared to centrifugal separation [18]. More specifically, superparamagnetic iron oxide particles in 
nano regime are extensively used in bioseperation for their well-established biocompatibility [19]. In addition, due to superparamagnetism of inorganic cores, recovery and further usage of these solids can be facilely achieved by applying external magnetic field [20].

In this work, a new magnetic micro-dimensional material with surface active boronic acid groups, magnetic poly(ethyleneglycol dimethylmethacrilate-vinylphenylboronicacid), m-poly(EGDMAVPBA), was produced by suspension polymerization technique in which the ferroferric oxide $\left(\mathrm{Fe}_{3} \mathrm{O}_{4}\right)$ superparamagnetic nanoparticles was incorporated during the synthesis and m-poly (EGDMA-VPBA) was characterized by FT-IR, $\mathrm{N}_{2}$ sorption, BET, ESR, Elemental analysis, ICP, Thermogravimetric analyses to obtain information about its structural, morphological and magnetic properties. The material was doped with sulphuric acid at several molar percentages and its structural and catalytic properties are discussed for the esterification of propionic acid with methanol.

\section{EXPERIMENTAL}

\section{1. Preparation of M-Poly(Egdma-Vpba) And Its $\mathrm{H}_{2} \mathrm{SO}_{4}$ Doped Forms}

The m-poly(EGDMA-VPBA) micro-dimensional particles (average diameter, 10-50 $\mu \mathrm{m}$ ) were synthesised by copolymerizing EGDMA $(21,2 \mathrm{mmol})$ with p-VPBA $(3,38 \mathrm{mmol})$ and $\mathrm{Fe}_{3} \mathrm{O}_{4}$ in the presence of the initiator AIBN and stabilizer poly(vinyl alcohol) [PVAL]. Table 1 shows recipe and polymerization conditions for preparation of the m-poly(EGDMA-VPBA) micro-dimensional particles. $\mathrm{H}_{2} \mathrm{SO}_{4}$ doped m-poly(EGDMA-VPBA) acid catalysts were prepared by mixing of different percentages of $\mathrm{H}_{2} \mathrm{SO}_{4}$ solution (5\%,10\% and 20\%, respectively) with m-poly(EGDMA-VPBA) at $298 \mathrm{~K}$ in a sealed cylindrical pyrex reactor for $2 \mathrm{~h}$. The solid was filtered and vacuum dried at $343 \mathrm{~K}$ overnight.

\section{2. Characterization}

Nitrogen adsorption and desorption isotherms at $77.4 \mathrm{~K}$ were measured using Quantachrome Corporation, Autosorb-6 system. Surface area was calculated by the Brunauer-Emmett-Teller (BET) method, and pore size distributions was determined using the Barret-Joyner-Halenda (BJH) model on the desorption branch. The surface structures of the micro-dimensional particles were visualized and examined by scanning electron microscopy (SEM, CARL ZEIss EVO 40, UK). The presence of magnetite nano-powders in the particles was investigated with an electron spin resonance (ESR) spectrophotometer (EL 9, Varian, USA).

FT-IR spectrums were recorded with ATR on a Perkin Elmer Spectrum 100 spectrophotometer. Bor composition was measured using inductively coupled plasma -atomic emission spectrometry (ICPAES; Shimazu ICPS-1000 IV). In order to test whether sulphur enters to the polymeric structure, mpoly(EGDMA-VPBA) and its $\mathrm{H}_{2} \mathrm{SO}_{4}$ doped (5\%,10\% and 20\%, respectively) forms were subjected to elemental analysis with LECO CHNS-932 model elemental analyzer. The acid exchange capacities of the $\mathrm{H}_{2} \mathrm{SO}_{4}$ doped m-poly(EGDMA-VPBA) were measured by means of titration, using sodium chloride as exchange agent. In a typical experiment, $0.05 \mathrm{~g}$ of solid was added to $15 \mathrm{~g}$ of aqueous solution of sodium chloride $(1 \mathrm{M})$. The resulting suspension was allowed to equilibrate and thereafter titrated potentiometrically by drop-wise addition of $0.01 \mathrm{M} \mathrm{NaOH}$ (aq) [21].

\section{3. General Prosedure for the Esterification of Propionic Acid with Methanol}

In a typical procedure, a mixture of propionic acid $(3.8 \mathrm{~mL})$ and $\mathrm{H}_{2} \mathrm{SO}_{4}$ doped m-poly(EGDMA-VPBA) $(0.5 \mathrm{~g})$ in 1,4-dioxane $(44.2 \mathrm{~mL})$ was placed in a round bottom flask in the shaking water bath the temperature of which was controlled within $\pm 0.1 \mathrm{C}^{0}$ at $250 \mathrm{rpm}$ shaking speed. The suspension was preheated to the reaction temperature from 50 to $70{ }^{\circ} \mathrm{C}$ by $10{ }^{\circ} \mathrm{C}$ intervals and the esterification was commenced by injecting the preheated methanol $(2.0 \mathrm{~mL})$ into the mixture. This was considered as the 
zero time for a run. The total liquid volume was $50 \mathrm{~cm}^{3}$. Stoichiometric ratio of propionic acid to methanol was (1:1) and 1,4-dioxane was used as solvent in all experiments. Conversion of the reaction was monitored by titration using standard $0.1 \mathrm{M}$ sodium hydroxide. To calculate the apparent activation energy the reaction temperature was changed from 50 to $70{ }^{\circ} \mathrm{C}$ by keeping the same experimental conditions.

\section{RESULTS AND DISCUSSION}

The suspension polymerization procedure provided cross-linked m-poly(EGDMA-VPBA) microdimensional particles. The $\mathrm{N}_{2}$ adsorption/desorption isotherm and corresponding pore size distribution curve for the m-poly(EGDMA-VPBA) are shown in Figure $1 \mathrm{a}-\mathrm{b}$. The BET surface area $\left(S_{B E T}\right)$, pore volume $\left(V_{P}\right)$ and pore size are given in Table 2. As shown in Figure 1a, the m-poly(EGDMA-VPBA) micro-dimensional particles are found to be type IV (based on IUPAC classification) isotherms for the typical hysteresis loop in the mesopore range. We can see that the adsorption at relative pressure below 0.2 , which is ascribed to micropore adsorption. Along with the increase of relative pressure, increases in adsorption capacity are caused by the monolayer/multilayer adsorptions of nitrogen molecules on the mesopores [22-23]. Changing of pore sizes in the range of 1,8 nm (micro)-3.7 nm (meso) indicates that the magnetic particles contain both micropores and mesopores.
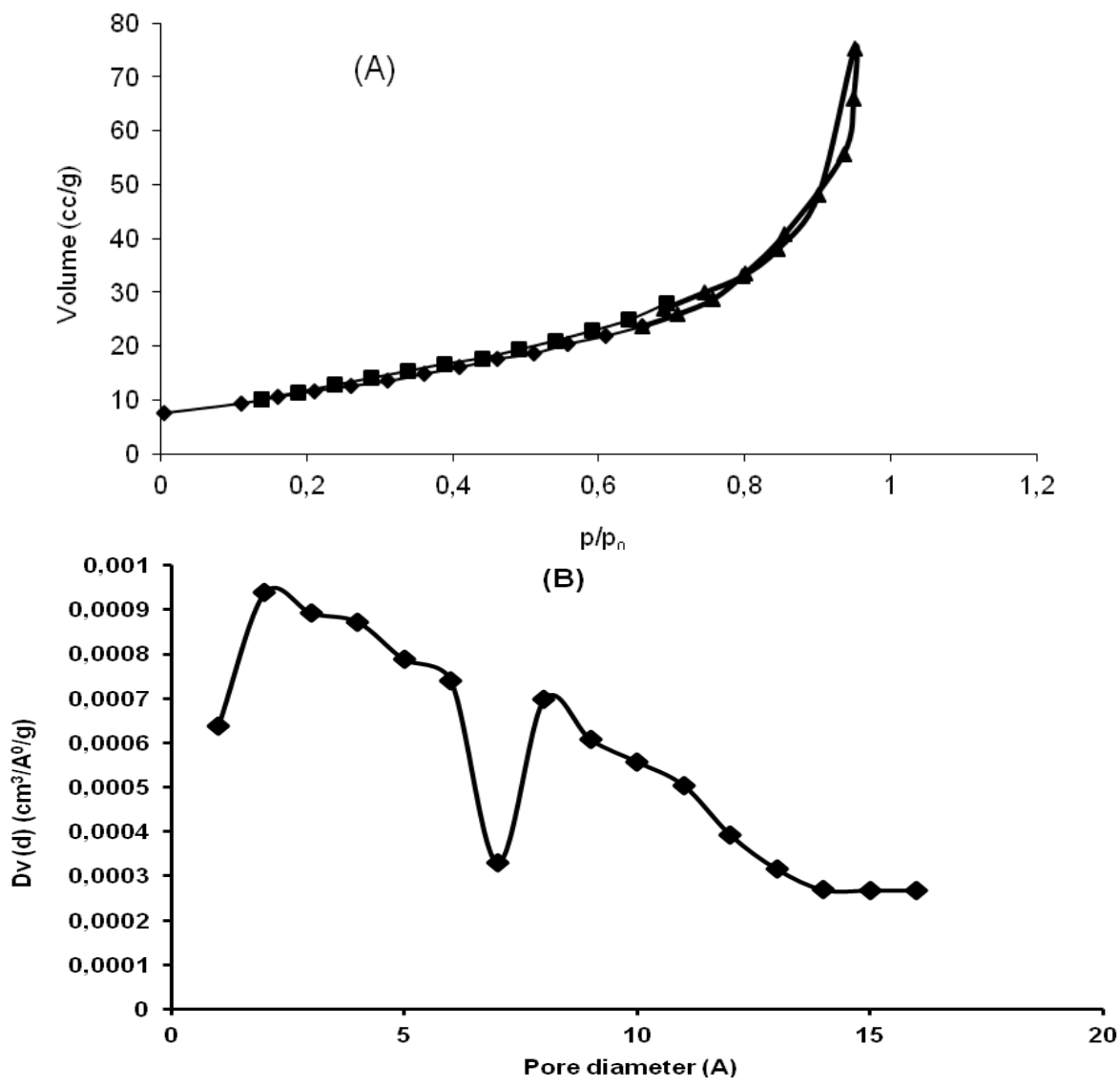

Figure 1. (A) Adsorption/desorption isotherms of nitrogen at $77.40 \mathrm{~K}$ and (B) pore size distrubition obtained by $\operatorname{Dv}(\mathrm{d})$ according to average pore diameter for the m-poly(EGDMA-VPBA)

The surface morphology and bulk structures of the m-poly(EGDMA-VPBA) micro-dimensional particles are visualized by SEM which are presented in Figure 2. All the micro-dimensional particles 
have rough surface and in the size range of $10-50 \mu \mathrm{m}$. In the SEM photograph of the bulk structure, a large quantity of well-distributed pores could be observed and they have netlike structure. The mpoly(EGDMA-VPBA) micro-dimensional particles prepared in this study had this characteristics and this property increases the specific surface area, the binding capacity of micro-dimensional particles, as well as the mass transfer rate of binding.

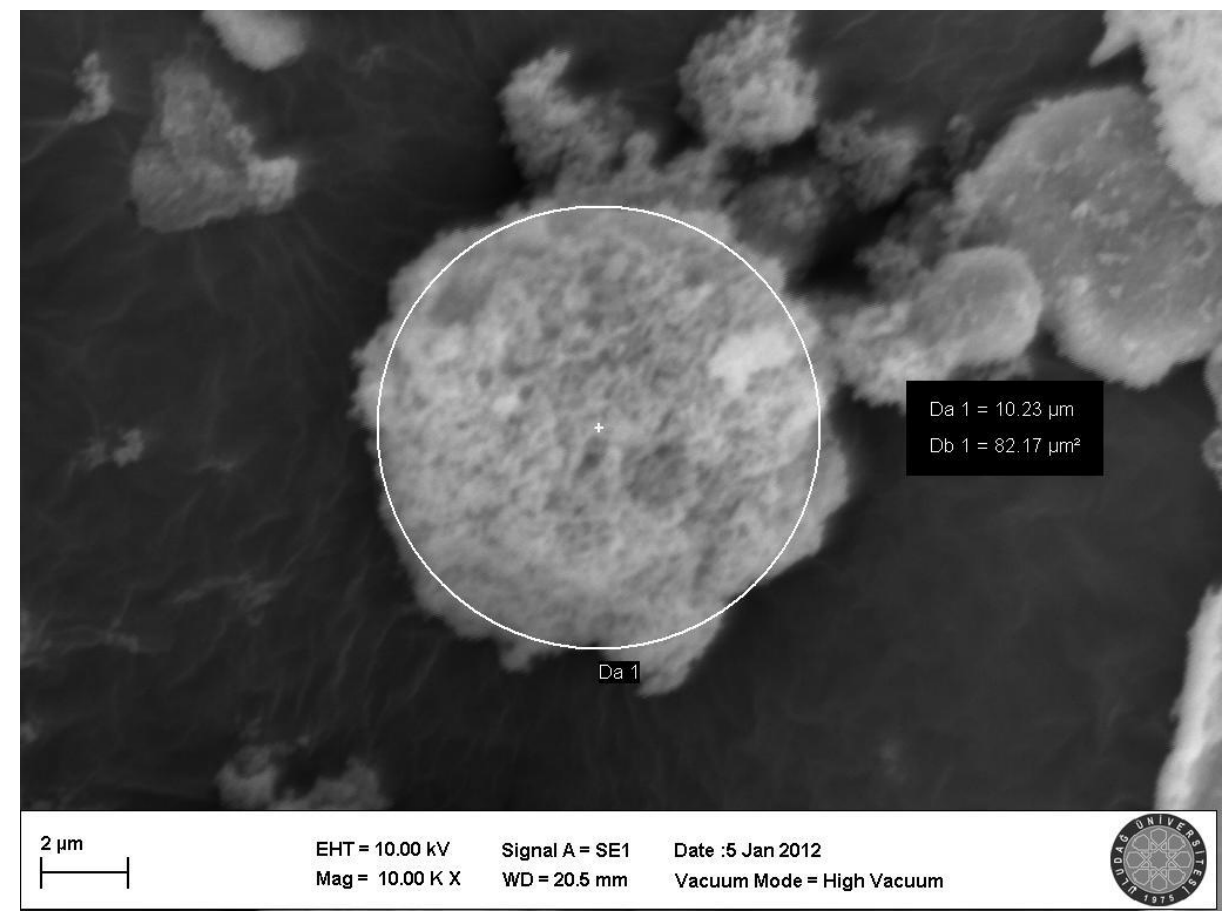

Figure 2. SEM photograph of the m-poly(EGDMA-VPBA) micro-dimensional particles

The equilibrium swelling ratio for the m-poly(EGDMA-VPBA) micro-dimensional particles is $73 \%$ in water. It should be also noted that these micro-dimensional particles are strong enough due to highly cross-linked structure therefore they are suitable for column applications.

Magnetic characteristics of magnetic materials are related to their type generally, while those of magnetic materials are usually related to the content of magnetic component inside. $\mathrm{So}, \mathrm{Fe}_{3} \mathrm{O}_{4}$ content is very important to the magnetic responsibility of magnetic materials. In general, the higher $\mathrm{Fe}_{3} \mathrm{O}_{4}$ content shows the stronger magnetic responsibility. For this reason, the average $\mathrm{Fe}_{3} \mathrm{O}_{4}$ content of the mpoly(EGDMA-VPBA) micro-dimensional particles was determined by density analysis. The hydrated density of the m-poly(EGDMA-VPBA) micro-dimensional particles measured at $25^{\circ} \mathrm{C}$ was $1.71 \mathrm{~g} \mathrm{~mL}^{-}$ ${ }^{1}$. By the same procedure, the density of $\mathrm{Fe}_{3} \mathrm{O}_{4}$ particles was found to be $4.94 \mathrm{~g} \mathrm{~mL}^{-1}$ at $25^{\circ} \mathrm{C}$. The density of non-magnetic poly(EGDMA-VPBA) micro-dimensional particles measured at $25^{\circ} \mathrm{C}$ was 1.08 $\mathrm{g} / \mathrm{mL}$. The magnetic particles volume fraction in the m-poly(EGDMA-VPBA) micro-dimensional particles can be calculated from the following equation derived from the mass balance:

$$
\phi=\frac{\rho_{\mathrm{C}}-\rho_{\mathrm{M}}}{\rho_{\mathrm{C}}-\rho_{\mathrm{A}}}
$$

where, $\rho_{\mathrm{A}}, \rho_{\mathrm{C}}$ and $\rho_{\mathrm{M}}$ are the densities of non-magnetic poly(EGDMA-VPBA) micro-dimensional particles, $\mathrm{Fe}_{3} \mathrm{O}_{4}$ nanopowder, and the m-poly(EGDMA-VPBA) micro-dimensional particles, respectively. Thus, with the density data mentioned above, the m-poly(EGDMA-VPBA) microdimensional particles gel volume fraction in the magnetic micro-dimensional particles was estimated to 
be $83.7 \%$. Therefore, the average $\mathrm{Fe}_{3} \mathrm{O}_{4}$ content of the resulting m-poly(EGDMA-VPBA) microdimensional particles was $16.3 \%$. The presence of magnetite nanopowder in the polymer structure was also confirmed by the ESR. The intensity of the magnetite peak against magnetic field (Gauss) is shown in Figure 3. A peak of magnetite was detected in the ESR spectrum. It should be noted that the nonmagnetic beads cannot be magnetized under this condition. It reflects response ability of magnetic materials to the change of external magnetic field firstly and it characterizes the ability of magnetic materials to keep magnetic field strength when the external magnetic field is removed. In order to show the magnetic stability, the m-poly(EGDMA-VPBA) micro-dimensional particles were kept in distilled water and ambient air for 3 months, and the same ESR spectrum was obtained. With the goal of testing the mechanical stability of the m-poly(EGDMA-VPBA) micro-dimensional particles, a bead sample was treated in a ball mill for $12 \mathrm{~h}$. SEM photographs show that a zero percentage of the sample was broken. The $\mathrm{g}$ factor given in Figure 3 can be considered as quantity characteristic of the molecules in which the unpaired electrons are located, and it is calculated from Eq. (2). The measurement of the $g$ factor for an unknown signal can be a valuable aid in the identification of a signal. In the literature, the $\mathrm{g}$ factor for $\mathrm{Fe}^{+3}$ is determined within the range of 1.4-3.1 for low spin and 2.0-9.7 for high spin complexes. The $\mathrm{g}$ factor was found to be 2.5 for the m-poly(EGDMA-VPBA) micro-dimensional particles.

$\mathrm{g}=\mathrm{h} \vartheta / \beta \mathrm{H}_{\mathrm{r}}$

Here, $\mathrm{h}$ is the Planck constant $\left(6.626 \times 10^{-27} \mathrm{erg} \mathrm{s}^{-1}\right) ; \beta$ is Universal constant $\left(9.274 \times 10^{-21} \mathrm{erg} \mathrm{G}^{-1}\right)$; is frequency $\left(9.707 \times 10^{9} \mathrm{~Hz}\right)$ and $\mathrm{H}_{\mathrm{r}}$ is resonance of magnetic field $(\mathrm{G})$.

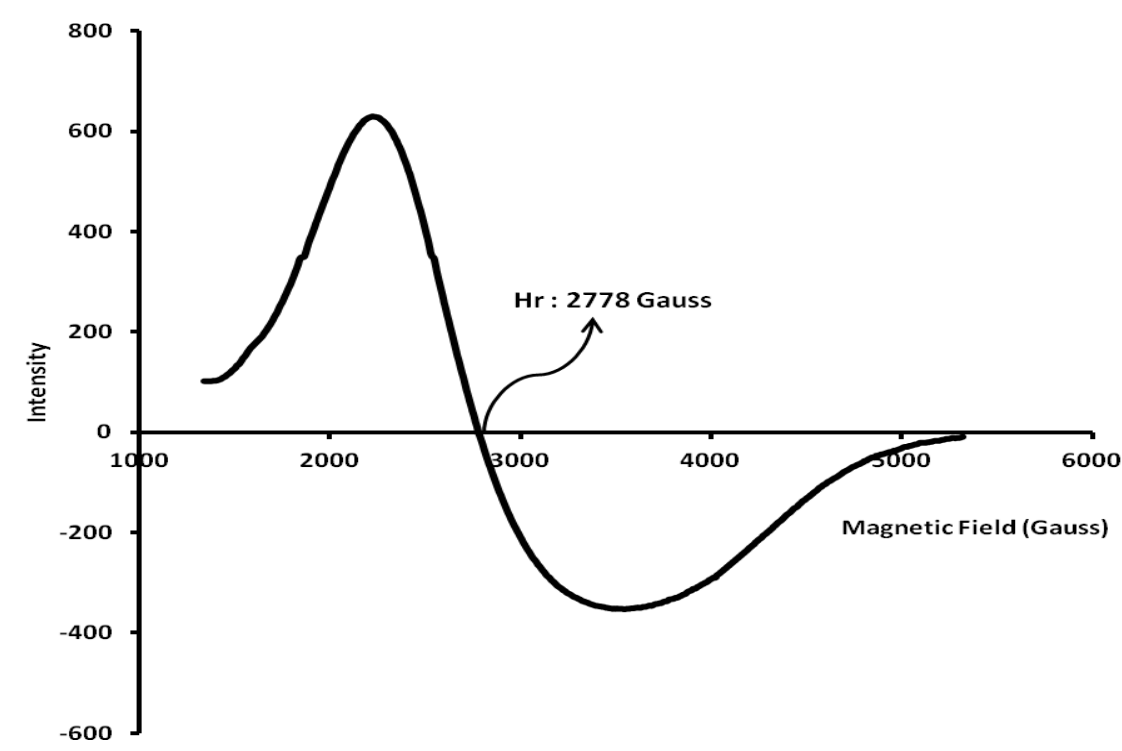

Figure 3. ESR spectrum of the m-poly(EGDMA-VPBA) micro-dimensional particles

All samples were characterized by FT-IR (Figure 4) including the pristine polymer (a) and 5\%-20\% $\mathrm{H}_{2} \mathrm{SO}_{4}$ doped m-poly(EGDMA-VPBA) (b-d) micro-dimensional particles. Bands at 1450 and $2950 \mathrm{~cm}^{-}$ ${ }^{1}$, typical for $\mathrm{C}-\mathrm{H}$ and phenyl groups [24] were recorded for all samples. The bands due to $\mathrm{C}=\mathrm{O}$ stretching at $1720 \mathrm{~cm}^{-1}$, C-O vibrations at $1140 \mathrm{~cm}^{-1}$ for EGDMA were also observed for all samples independent of sulfonation. Additionally, a broadening of the band around at $3500 \mathrm{~cm}^{-1}$ can be related to hydrogen bonding network formation [25]. The introduction of $\mathrm{Fe}_{3} \mathrm{O}_{4}$ to the poly(EGDMA-VPBA) was confirmed by the band at $580 \mathrm{~cm}^{-1}$ assigned to the Fe-O absorption band (Samples a-d). After blending the polymer 
with $\mathrm{H}_{2} \mathrm{SO}_{4}$, the strong absorption peak at $1030 \mathrm{~cm}^{-1}$ most probably belongs to $-\mathrm{SO}_{3}^{-}\left(\mathrm{H}^{+}\right)$[26-28]. The intensity of $-\mathrm{SO}_{3}-\left(\mathrm{H}^{+}\right)$peak also increases in parallel with the increase of molar ratio ${ }^{-} \mathrm{H}_{2} \mathrm{SO}_{4}$ in the blends.

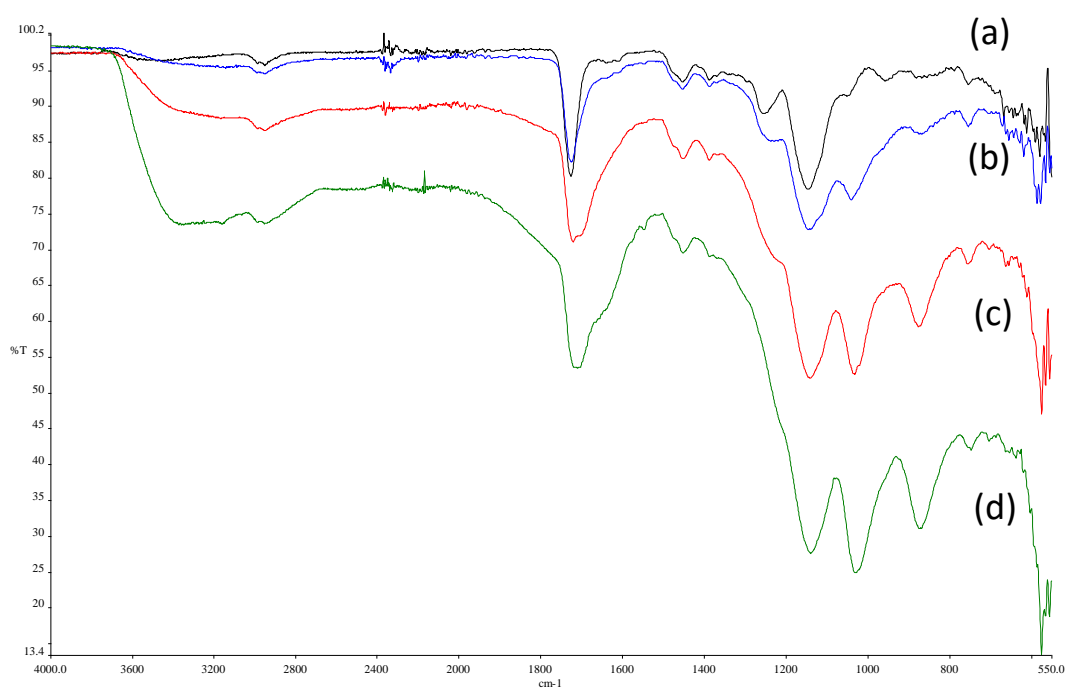

Figure 4. FT-IR spectra of m-poly(EGDMA-VPBA) (a) and its $5 \%$ (b), $10 \%$ (c) and $20 \%$ (d) $\mathrm{H}_{2} \mathrm{SO}_{4}$ doped forms

Boron content of m-poly(EGDMA-VPBA) was estimated to be $0.5 \mathrm{wt} \%$ by ICP-AES. This result indicates that VPBA was successfully incorporated into the matrix in the synthesis system.

Elemental analysis was applied for the determination of the changes in the $\mathrm{C}, \mathrm{H}$, and $\mathrm{S}$ content of the $\mathrm{m}$ poly(EGDMA-VPBA) and its $\mathrm{H}_{2} \mathrm{SO}_{4}$ modified forms (Table 3). This is clear evidence indicating that $\mathrm{H}_{2} \mathrm{SO}_{4}$ is bonded to the polymer, thus being accessible and useful for adsorption and catalytic reaction processes. The data show more significant increase in the sulphur content after $\mathrm{H}_{2} \mathrm{SO}_{4}$ loading on the polymer. This effect is in good accordance with ion-exchange capacities measured by titration (Table 3 ).

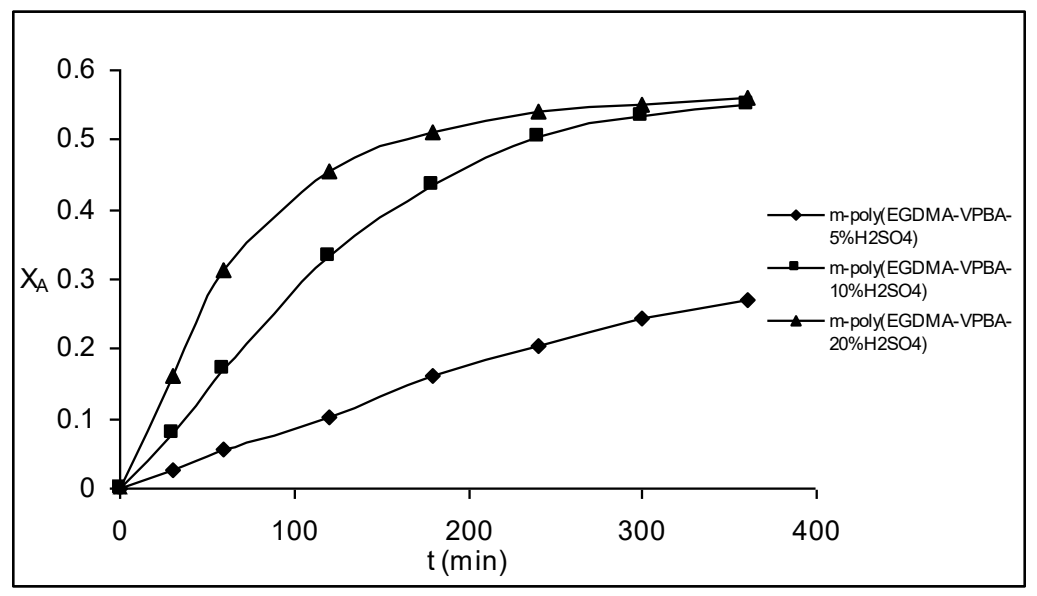

Figure 5. Catalytic conversion of $5 \%, 10 \%$ and $20 \% \mathrm{H}_{2} \mathrm{SO}_{4}$ doped m-poly(EGDMA-VPBA) catalysts (1:1 molar ratio, $60{ }^{\circ} \mathrm{C}, 250$ shaking speed)

Figure 5 shows the evolution of conversion of propionic acid with reaction time in the batch reaction performed at $60^{\circ} \mathrm{C}$ over $5 \%, 10 \%$ and $20 \% \mathrm{H}_{2} \mathrm{SO}_{4}$ doped m-poly(EGDMA-VPBA). As the loading of 
$\mathrm{H}_{2} \mathrm{SO}_{4}$ increases, reaction rates and conversion values increase. In order to compare these different $\mathrm{H}_{2} \mathrm{SO}_{4}$ loaded catalysts thermodynamically, model esterification reaction, known to be reversible reaction of second order [29-31] was performed at different temperatures from 50 to $70{ }^{\circ} \mathrm{C}$ by keeping

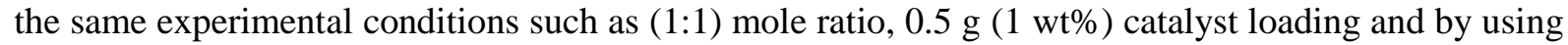
1,4-dioxane as solvent. Reaction rate constants (k) were calculated according to pseudo-homogeneous second order rate equation [32-33]:

$\ln \frac{X_{A, e}-\left(2 X_{A, e}-1\right) X_{A}}{X_{A, e}-X_{A}}=2 k\left(\frac{1}{X_{A, e}}-1\right) C_{A, 0} t$

where $\mathrm{X}_{\mathrm{A}}$, fractional conversion of propionic acid:

$$
X_{A}=\frac{C_{A, 0}-C_{A}}{C_{A, 0}}
$$

As the reaction temperature increased (Figure 6), the reaction kinetics was faster, but equilibrium conversion was nearly the same in the range of temperatures studied in this work.

$$
\ln \mathrm{k}=\ln \mathrm{A}-\frac{\mathrm{E}_{\mathrm{A}}}{\mathrm{R}}\left(\frac{1}{\mathrm{~T}}\right)
$$

The activation energy obtained for $10 \% \mathrm{H}_{2} \mathrm{SO}_{4}$ doped m-poly(EGDMA-VPBA) is $28.4 \mathrm{~kJ} \mathrm{~mol}^{-1}$.

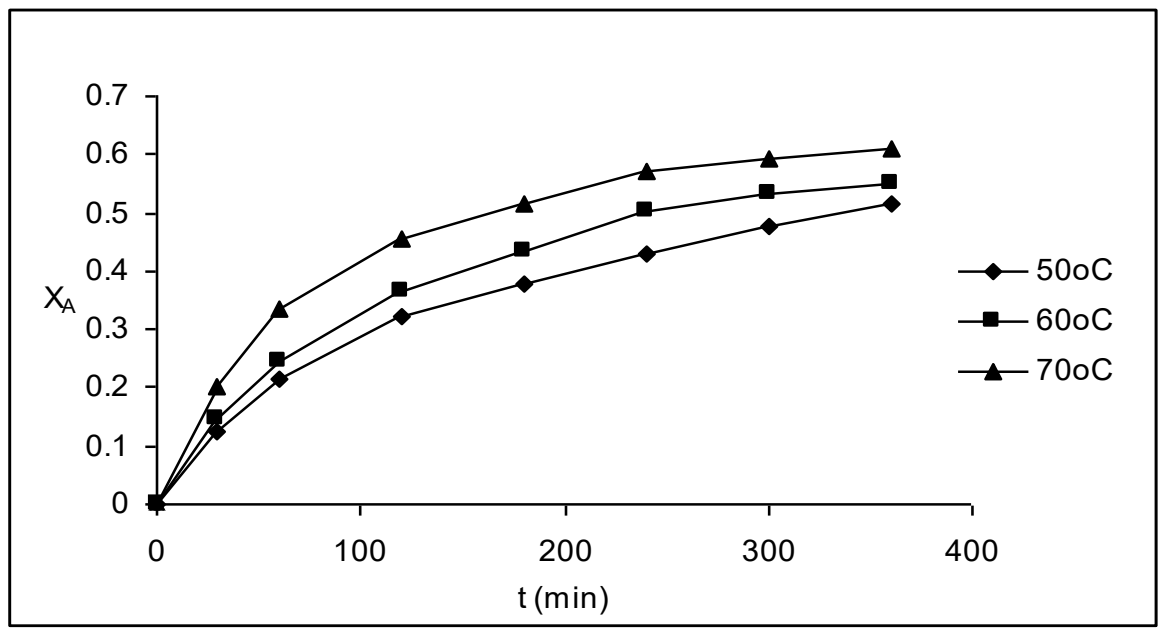

Figure 6. Effect of temperature on the conversion of propionic acid over $10 \% \mathrm{H}_{2} \mathrm{SO}_{4}$ doped mpoly(EGDMA-VPBA) catalyst (1:1 molar ratio, 250 shaking speed)

In order to test the suitability of the kinetic model (Eq. 3) for representation of the rate data, the plot was made of the left-hand side versus time with regression coefficients for different temperatures (Figure 7). The values of $\mathrm{k}$ for the m-poly(EGDMA-VPBA- $10 \% \mathrm{H}_{2} \mathrm{SO}_{4}$ ) were calculated from the slope of the lines and found to be $4.073 \times 10^{-3} \mathrm{~L} \mathrm{~mol}^{-1} \mathrm{~min}^{-1}, 5.188 \times 10^{-3} \mathrm{~L} \mathrm{~mol}^{-1} \mathrm{~min}^{-1}$, and $7.546 \times 10^{-3} \mathrm{~L} \mathrm{~mol}^{-1} \mathrm{~min}^{-1}$ for 50, 60, and $70{ }^{\circ} \mathrm{C}$, respectively. The data fall on straight lines for m-poly(EGDMA-VPBA-10\% $\mathrm{H}_{2} \mathrm{SO}_{4}$ ) confirming the applicability of the model for this reaction. 


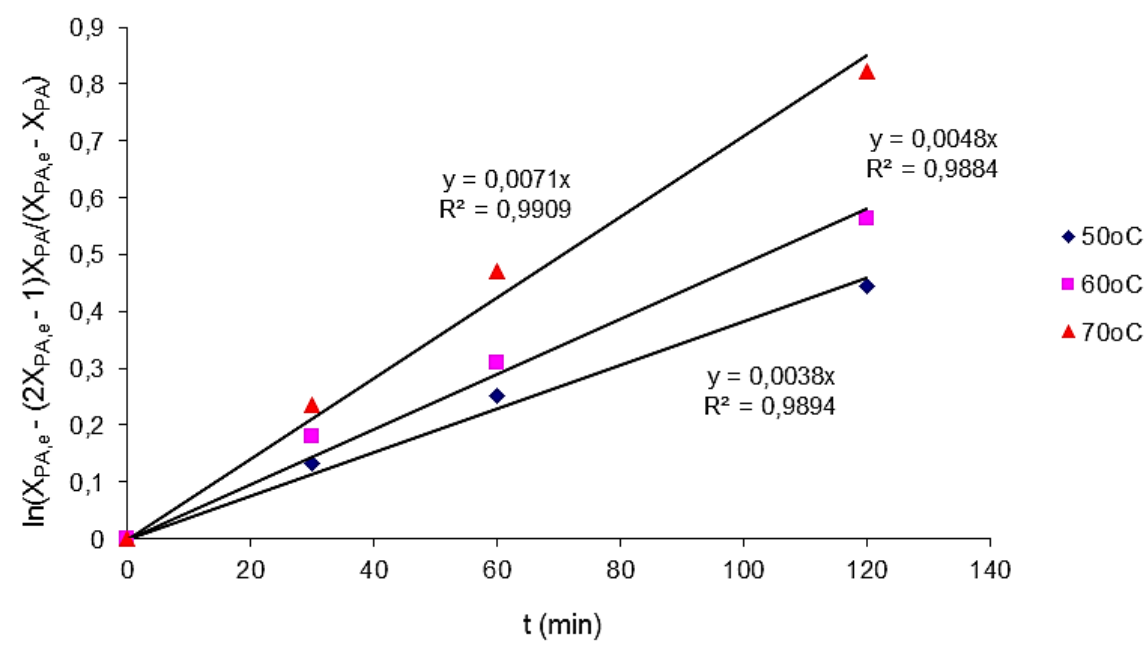

Figure7. Testing of kinetic model for different temperatures over m-poly(EGDMA-VPBA-10\% $\mathrm{H}_{2} \mathrm{SO}_{4}$ ) catalyst (1:1 molar ratio, 250 shaking speed)

\section{CONCLUSIONS}

In this work, the catalyst possessing strong acidity was prepared by impregnating $\mathrm{H}_{2} \mathrm{SO}_{4}$ onto the mpoly(EGDMA-VPBA). In the esterification of propionic acid with methanol at $60{ }^{\circ} \mathrm{C}$ of reaction temperature, $300 \mathrm{~min}$ of reaction time, 1:1 molar ratio of propionic acid with methanol, and $1.0 \mathrm{wt} \%$ of the catalyst content in reaction media, catalyst exhibited conversion of propionic acid of $55 \%$. The result of field dependence of magnetization was consistent with the microscopic observation. This work demonstrates the potential of m-poly(EGDMA-VPBA) micro-dimensional materials for rational design of heterogeneous catalyst. $\mathrm{H}_{2} \mathrm{SO}_{4}$ doped poly(EGDMA-VPBA) improved the esterification activity because of the increasing of acid sites and, therefore has potential for application in esterification reactions.

\section{ACKNOWLEDGMENT}

This work was supported by the Research Foundation of Uludag University (Project No: OUAP(F)2012/28).

\section{REFERENCES}

[1] Lilja J, Murzin DY, Salmi T, Aumo J, Maki-Arvela P, Sundell M. Esterification of different acids over heterogeneous and homogeneous catalysts and correlation with the Taft equation. Journal of Molecular Catalysis A 2002; 182-183: 555-563.

[2] Liu WT, Tan CS. Liquid-phase esterification of propionic acid with n-butanol. Industrial\&Engineering Chemistry Research 2001; 40: 3281-3286.

[3] Erdem B, Cebe M. Kinetics of Esterification of Propionic Acid with n-amyl Alcohol in the Presence of Cation Exchange Resin. Korean Journal of Chemical Engineering 2006; 23(6): 896-901.

[4] Teo HTR, Saha B. Heterogeneous catalysed esterification of acetic acid with isoamyl alcohol: kinetic studies. Journal of Catalysis 2004; 228: 174-182. 
Kara and Erdem / Anadolu Univ. J. of Sci. and Technology - A-Appl. Sci. and Eng. 17 (5) - 2016

[5] Lilja J, Warna J, Salmi T, Pettersson LJ, Ahlkvist J, Grenman H, Ronnholm, M, Murzin, DY. Esterification of Propanoic Acid with Ethanol, 1-Propanol and Butanol over a Heterogeneous Fiber Catalyst. Chemical Engineering Journal 2005; 115:1-12.

[6] Peters TA, Benes NE, Holmen A, Keurentjes JTF. Comparison of commercial solid acid catalysts for the esterification of acetic acid with butanol. Applied Catalysis A: General 2006; 297(2): 182-188.

[7] Altıokka MR, Çıtak A. Kinetics Study of Esterification of Acetic Acid With Isobutanol in The Presence of Amberlite Catalyst. Applied Catalyst A:General 2003; 239: 141-148.

[8] Sow B, Hamoudi S, Zahedi-Naki MH, Kaliaguine S. 1-Butanol Etherification Over Sulfonated Mesostructured Silica and Organo-Silica. Microporous and Mesoporous Materials 2005; 79(1):129-136.

[9] Kara A, Erdem B. Synthesis, characterization and catalytic properties of sulfonic acid functionalized magnetic-poly(divinylbenzene-4-vinylpyridine) for esterification of propionic acid with methanol. Journal of Molecular Catalysis A: Chemical 2011; 349: 42-47.

[10] Hazot P, Delair T, Elaissari A, Chapel JP, Pichot C. Functionalization of poly(Nethylmethacrylamide) thermosensitive particles by phenylboronic acid. Colloid and Polymer Scienc 2002; 280: 637-646.

[11] Koyama T, Terauchi K. Synthesis and application of boronic acid- immobilized porous polymer particles: a novel packing for high-performance liquid affinity chromatography. Journal of Chromatography B: Biomedical Sciences and Applications 1996; 679: 31-40.

[12] Elmas B, Onur MA, Senel S, Tuncel A. Thermosensitive N-isopropylacrylamide vinylphenyl boronic acid copolymer latex particles for nucleotide isolation. Colloids and Surfaces A: Physicochemical and Engineering Aspects 2004; 232: 253-259.

[13] Uusi-Oukari M, Ehnholm C, Jauhiainen M. Inhibition of hepatic lipase by m-aminophenylboronate application of phenylboronate affinity chromatography for purification of human postheparin plasma lipases. Journal of Chromatography B: Biomedical Sciences and Applications 1996; 82: 233-242.

[14] Kitano H, Kuwayama M, Kanayama N, Ohno K. Interfacial Recognition of Sugars by Novel Boronic Acid-Carrying Amphiphiles Prepared with a Lipophilic Radical Initiator. Langmuir 1998; 14: 165-170.

[15] Hall DG. Boronic acids. Wiley-VCH 2005; 1-568.

[16] Lousrance WW. Ein neuer weg zu benzimidazoliumsalzen. Tetrahedron Letters 1977; 39: 34533456.

[17] Ishihara K, Ohora S, Yamamato H. 3,4,5-Trifluorobenzeneboronic Acid as an Extremely Active Amidation Catalyst. The Journal of Organic Chemistry 1996; 61: 4196-4197.

[18] Wei S, Zhu Y, Zhang Y, Xu J. Preparation and characterization of hyperbranched aromatic polyamides/Fe3O4 magnetic nanocomposite. Reactive \& Functional Polymers 2006; 66: 1272-1277.

[19] Perez JM, Loughin TO, Simeone FJ, Weissleder R, Josephson L, DNA-based magnetic nanoparticle assembly acts as a magnetic relaxation nanoswitch allowing screening of DNA-cleaving agents. Journal of the American Chemical Society 2002; 124: 2856-2857. 
Kara and Erdem / Anadolu Univ. J. of Sci. and Technology - A-Appl. Sci. and Eng. 17 (5) - 2016

[20] Mohapatra S, Panda N, Pramanik P. Boronic acid functionalized superparamagnetic iron oxide nanoparticle as a novel tool for adsorption of sugar. Materials Science and Engineering C 2009; 29: 2254-2260.

[21] Margolese D, Melero JA, Christiansen SC, Chmelka BF, Stucky GD. Direct syntheses of ordered SBA15 mesoporous silica containing sulfonic acid groups. Chemistry of Materials 2000; 12(8): 2448-2459.

[22] Erdem B, Kara A. Sulfonic acid functionalized poly(ethylene glycol dimethacrylate-1-vinyl-1,2,4triazole) as a high-performance solid acid catalyst for the esterification of lactic acid with methanol. Journal of Colloid and Interface Science 2012; 367: 394-397.

[23] Xia K, Gao Q, Jiang J, Hu J. Hierarchical porous carbons with controlled micropores and mesopores for supercapacitor electrode materials. Carbon 2008; 46: 1718-1726.

[24] Szegedi A, Popova M, Goshev I, Mihaly J. Effect of amine functionalization of spherical MCM41 and SBA-15 on controlled drug release. Journal of Solid State Chemistry 2011; 184: 1201-1207.

[25] Erdem B, Kara A. Sulfonic acid functionalized poly (ethylene glycol dimethacrylate-1-vinyl-1,2,4triazole) as an efficient catalyst for the synthesis of methyl propionate. Reactive \& Functional Polymers 2011; 71: 219-224.

[26] Mu B, Wang T, Wu Z, Shi H, Xue D, Liu P. Fabrication of functional block copolymer grafted superparamagnetic nanoparticles for targeted and controlled drug delivery. Colloids and Surfaces A: Physicochemical and Engineering Aspects 2011;375: 163-168.

[27] Can K, Ozmen M, Ersoz M. Immobilization of albumin on aminosilane modified superparamagnetic magnetite nanoparticles and its characterization. Colloids and Surfaces B: Biointerfaces 2009; 71: 154-159.

[28] Aslan A, Çelik SÜ, Şen Ü, Haser R, Bozkurt A. Intrinsically proton-conducting poly (1-vinyl-1, 2, 4-triazole)/triflic acid blends. Electrochimica Acta 2009; 54: 2957-2961.

[29] Sing KSW. Reporting physisorption data for gas/solid systems with special reference to the determination of surface area and porosity (Provisional). Pure \& Applied Chemistry 1982; 54(11): 22012218.

[30] Liu Y, Lotero E, Goodwin Jr JG. Effect of Water on Sulfuric Acid Catalyzed Esterification. Journal of Molecular Catalysis A: Chemical 2006; 245: 132-140.

[31] Yixin Q, Shaojun P, Shui W, Zhiqiang Z, Jidong W. Kinetic Study of Esterification of Lactic Acid with Isobutanol and n-Butanol Catalyzed by Ion-exchange Resins. Chinese Journal of Chemical Engineering 2009;17(5): 773-780.

[32] Erdem B, Cebe M. Volumetric, Chromatographic, Refractometric Studies on the Esterification of Methanol with Acetic Acid in the Presence of Cation-Exchange Resins. Zeitschrift für Physikalische Chemie 2006; 220: 735-738.

[33] İzci A, Bodur F. Liquid-phase esterification of acetic acid with isobutanol catalyzed by ionexchange resins. Reactive \& Functional Polymers 2007; 67: 1458-1461. 